\title{
Identification of sulfated steroidal glycosides from the starfish Heliaster helianthus by electrospray ionization mass spectrometry
}

\author{
Marta S. Maier, ${ }^{* a}$ Romina Centurión, ${ }^{a, b}$ Claudia Muniain, ${ }^{b}$ Renato Haddad, \\ and Marcos N. Eberlin ${ }^{c}$ \\ ${ }^{a}$ Departamento de Química Orgánica and UMYMFOR (FCEN-CONICET), Facultad de \\ Ciencias Exactas y Naturales, Universidad de Buenos Aires, Pabellón 2, Ciudad Universitaria \\ (1428) Buenos Aires, Argentina \\ ${ }^{b}$ Museo Argentino de Ciencias Naturales "Bernardino Rivadavia”, Angel Gallardo 470 (1405) \\ Buenos Aires, Argentina \\ ${ }^{c}$ Universidade Estadual de Campinas, Cidade Universitária “Zeferino Vaz”,13083-970 \\ Campinas, SP, Brazil \\ E-mail:maier@qo.fcen.uba.ar
}

Dedicated to Professor Atta-ur-Rahman on his $65^{\text {th }}$ anniversary

\begin{abstract}
The starfish Heliaster helianthus contains Thornasteroside A (1) and Helianthoside (2) and its isomer (3) as the major sulfated steroidal glycosides. Saponin containing fractions obtained by purification of extracts of $H$. helianthus induced escape reactions and mortality in the limpets Siphonaria lessoni and Fissurella radiosa. ESI-MS and ESI-MS/MS were successfully applied to the rapid screening of two cytotoxic fractions obtained by purification of the ethanolic extracts of arms and central disks dissected from $H$. helianthus. Three major compounds were identified, together with minor sulfated steroidal mono- and diglycosides of polyhydroxysteroids.
\end{abstract}

Keywords: Starfish, Heliaster helianthus, sulfated glycosides, electrospray ionization tandem mass spectrometry

\section{Introduction}

Sulfated steroidal oligoglycosides (asterosaponins) have been recognized as predominant and characteristic metabolites of starfishes. ${ }^{1}$ Asterosaponins, which are responsible for the toxicity of these marine organisms, are accompanied by a variety of steroidal mono- and diglycosides and by free and sulfated polyhydroxysteroids in very complex mixtures of highly oxygenated compounds. Starfish extracts have drawn attention because of their wide spectrum of biological 
effects associated with antifungal, cytotoxic, hemolytic, cytostatic and immunomodulatory activities. $^{2}$ Recently, we have demonstrated the antifungal activity of two new sulfated hexaglycosides and two new sulfated polyhydroxylated steroidal xylosides isolated from the Patagonian starfish Anasterias minuta. ${ }^{3}$

In our continuing search for bioactive metabolites from echinoderms and aiming to elucidate the possible biological role of steroidal glycosides in starfish, we have focused our attention on the polar extracts of the limpet predatory starfish Heliaster helianthus (Lamarck, 1816), collected off Las Cruces, Chile. Previous work on this starfish led to the isolation of the common pentaglycoside Thornasteroside A (1) together with the sulfated polyhydroxylated steroidal xylosides Helianthoside (2) and its isomer (3) (Fig. 1). ${ }^{4,5}$
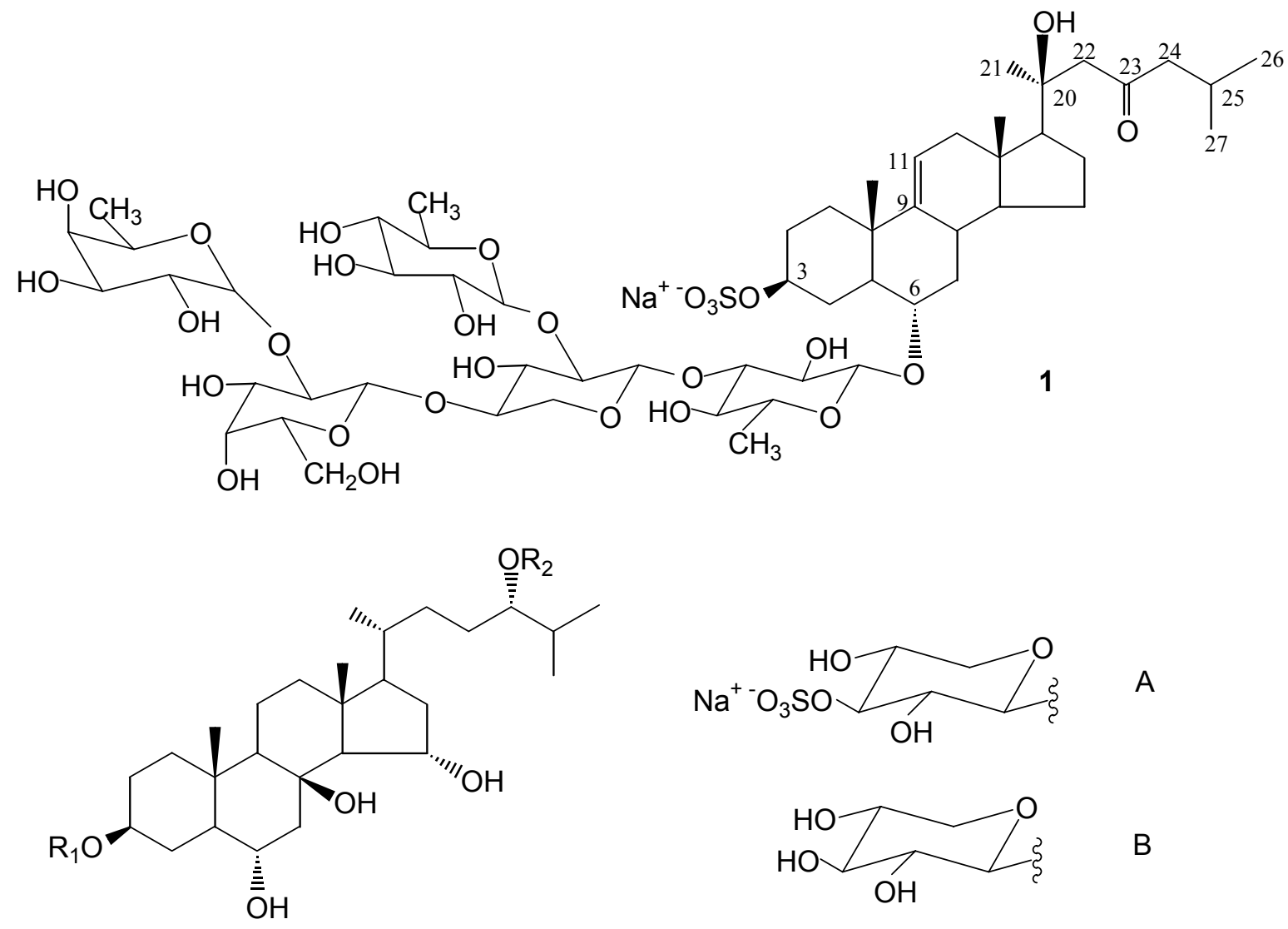

$2 \mathrm{R}_{1}=\mathrm{H}, \mathrm{R}_{2}=\mathrm{A}$

$3 \mathrm{R}_{1}=\mathrm{B}, \mathrm{R}_{2}=\mathrm{SO}_{3}{ }^{-} \mathrm{Na}^{+}$

Figure 1. Chemical structures of sulfated steroidal glycosides 1-3.

Previous field experiments demonstrated that the limpets Lottia orbignyi and Scurria viridula display active locomotor escape response following contact with homogenates of H. helianthus. ${ }^{6}$ Recently, we observed that saponin containing fractions obtained by purification of extracts of 
H. helianthus induce escape reactions and mortality in the limpets Siphonaria lessoni and Fissurella radiosa. ${ }^{7}$ To correlate the results of these field experiments with the saponin composition of the tested fractions, we used direct infusion electrospray ionization mass spectrometry as a rapid analytical tool to identify the bioactive compounds in the fractions. Mass spectrometry has played an important role in the structural analysis of natural products owing mainly to its high sensitivity, selectivity and low levels of sample consumption. With the development of soft ionization techniques such as electrospray ionization (ESI), rapid and direct analysis of polar, non-volatile and thermally labile classes of compounds has been achieved. ${ }^{8}$ Recently, ESI tandem mass spectrometry (ESI-MS/MS) has been shown to provide useful structural information on saponins in plant extracts. ${ }^{9}$

In the present work, we employed ESI mass (ESI-MS) and tandem mass spectrometries (ESIMS/MS) for analysis of the polar steroidal glycosides responsible of the toxicity of the purified fractions of the extract of $H$. helianthus.

\section{Results and Discussion}

The $n$ - $\mathrm{BuOH}$ extracts of the arms and central disks of $H$. helianthus exhibited cytotoxicity in the brine shrimp (Artemia salina L.) larvae mortality bioassay. ${ }^{10}$ Purification of both extracts by chromatography over Sephadex LH60 and further analysis by TLC and comparison with standards led to the isolation of fractions rich in polar steroidal oligoglycosides together with fractions containing predominantly steroidal monoglycosides. Two of these fractions (F4 and F8) were selected for ESI-MS studies to obtain molecular mass and structural information on the starfish steroidal glycoside mixtures.

Fraction F4 was obtained by purification of the $n$-BuOH extract of the arms and contained asterosaponins as the major components. The ESI-MS in the negative ion mode of this fraction (Fig. 2) displays an ion of $m / z 1243$ assigned to the corresponding anion $[\mathrm{M}-\mathrm{Na}]^{-}$of Thornasteroside A (1), the only asterosaponin reported so far from H. helianthus. ${ }^{4}$

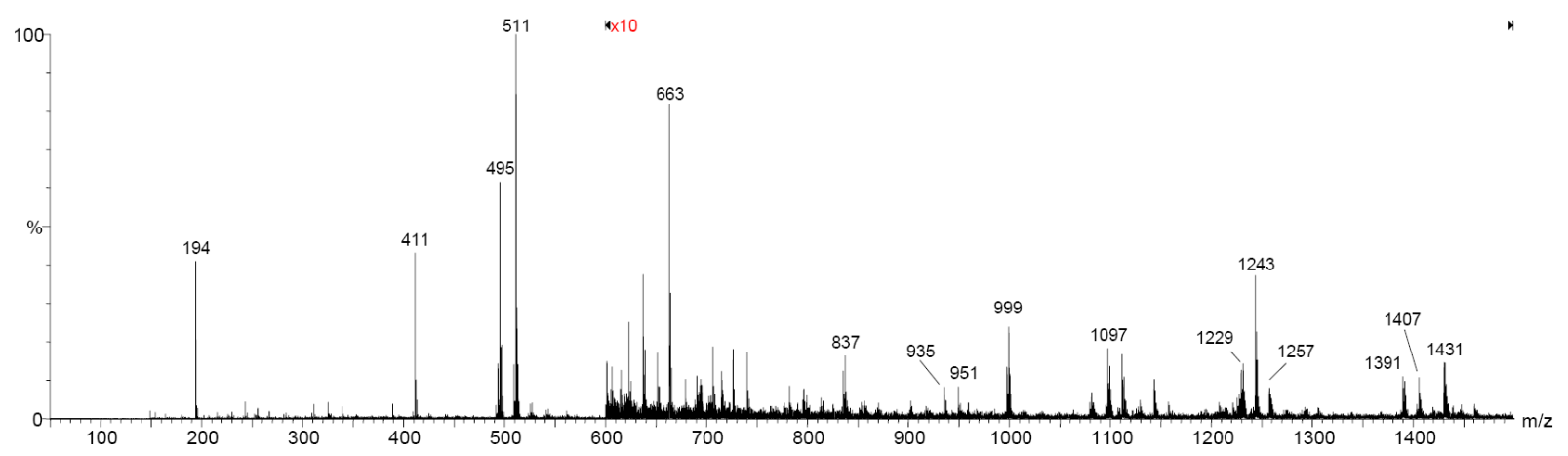

Figure 2. ESI-MS of fraction F4 in the negative ion mode. 
The ESI-MS/MS of the isolated ion of $\mathrm{m} / \mathrm{z} 1243$ (Fig. 3a) displays a fragment ion of $\mathrm{m} / \mathrm{z} 1143$ corresponding to the loss of a $\mathrm{C}_{6} \mathrm{H}_{12} \mathrm{O}$ molecule arising from $\mathrm{C}(20)-\mathrm{C}(22)$ bond cleavage and $1 \mathrm{H}$ transfer (retro aldol cleavage), characteristic of asterosaponins containing an aglycone with a 20hydroxy-23-oxo side chain. ${ }^{11}$ The major ion of $m / z 511$ in the ESI-MS of fraction F4 (Fig. 2) corresponds to the fragment ion of the sulfated aglycone of asterosaponin 1. ESI-MS/MS experiment of the isolated ion of $\mathrm{m} / \mathrm{z} 511$ (Fig. 3b) shows it to fragment to an ion of $\mathrm{m} / \mathrm{z} 411$ due to retro aldol cleavage of the aglycone side chain (loss of $\mathrm{C}_{6} \mathrm{H}_{12} \mathrm{O}$ ) and to a fragment ion of $\mathrm{m} / \mathrm{z}$ 97 attributed to $\mathrm{SO}_{4} \mathrm{H}^{-}$. In the ${ }^{13} \mathrm{C}-\mathrm{NMR}$ spectrum of fraction $\mathrm{F} 4$ signals at $\delta 13.8(\mathrm{C}-18), 22.7$ (C-26), 22.9 (C-27), 27.3 (C-21), 74.0 (C-20), 77.8 (C-3), 80.4 (C-6), 116.7 (C-11), 146.5 (C-9) and 211.9 (C-23) ppm are consistent with the presence of 5 $\alpha$-cholest-9(11)-en-23-one$3 \beta, 6 \alpha, 20 S$-triol 3-sulfate (Thornasterol A) as the aglycone in $\mathbf{1}{ }^{12}$
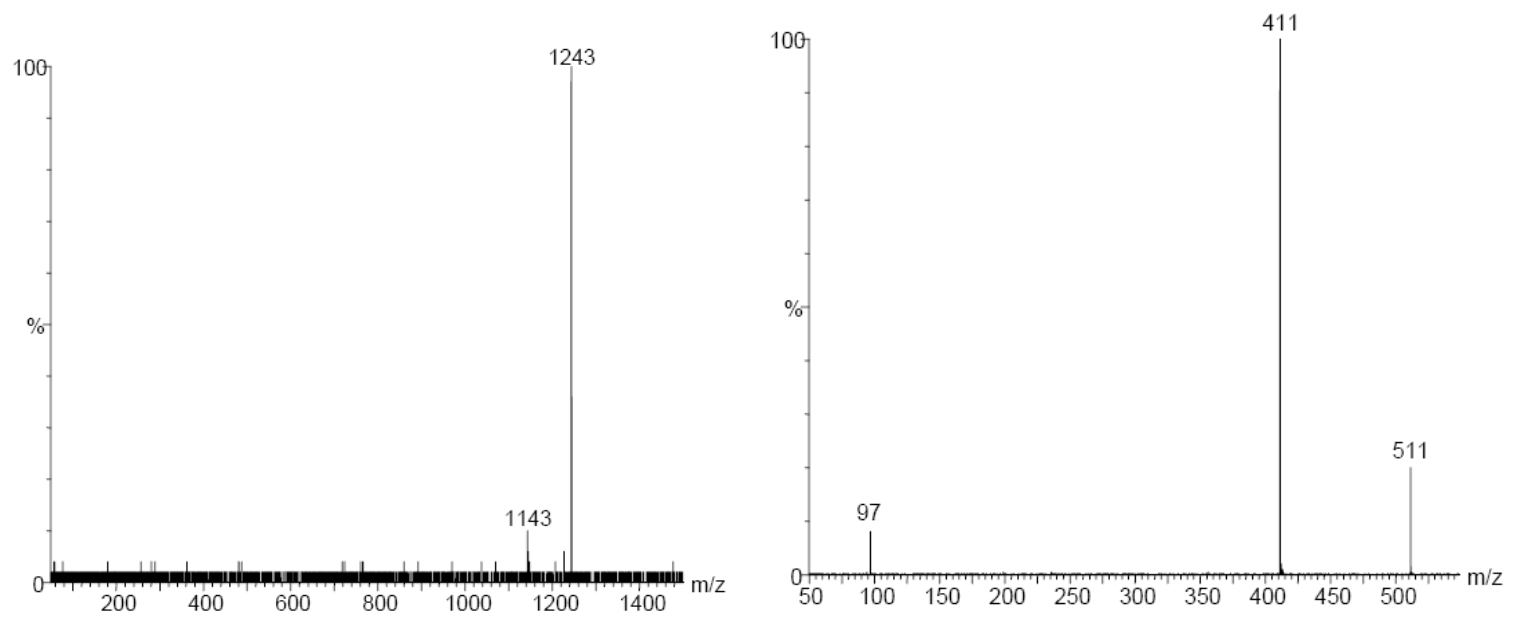

Figure 3. (a) ESI-MS/MS of the ion of $m / z$ 1243; (b) ESI-MS/MS of the ion of $m / z 511$.

The ESI-MS of fraction F4 (Fig. 2) detects ions arising from the cleavages of the glycosidic bonds from the terminal sugar moieties of asterosaponin 1, with charge located on the aglycone containing fragments. A fragment ion of $m / z 1097\left([\mathrm{M}-146-\mathrm{Na}]^{-}\right)$indicates loss of a terminal deoxyhexose residue (attributable to isomeric fucose or quinovose) whereas the fragment ions of $m / z 951\left([\mathrm{M}-146-146-\mathrm{Na}]^{-}\right)$and $935\left([\mathrm{M}-146-162-\mathrm{Na}]^{-}\right)$are consistent with the loss of terminal quinovose and fucose units and fucose and galactose, respectively. Figure 2 also shows ions of $\mathrm{m} / \mathrm{z} 999$ and 837 due to the retro aldol cleavage of the aglycone side chain $\left(\mathrm{C}_{6} \mathrm{H}_{12} \mathrm{O}\right.$ loss $)$ from fragment ions of $m / z 1097$ and 935, respectively.

The ion of $\mathrm{m} / \mathrm{z} 495$ in Fig. 2 could not be assigned to fragmentation of Thornasteroside A (1). ESI-MS/MS of this ion shows $\mathrm{SO}_{4} \mathrm{H}^{-}$of $\mathrm{m} / z 97$ as the only fragmentation product. The fragment ion of $\mathrm{m} / z 495$ has been detected as a characteristic ion in the FAB mass spectrum in negative ion mode of asterosaponins containing (20R)-5 $\alpha$-cholest-9(11)-en-23-one-3 $\beta, 6 \alpha$-diol 3 -sulfate as the aglycone. ${ }^{13} \mathrm{C}-\mathrm{NMR}$ analysis of fraction $\mathrm{F} 4$ shows the presence of signals at $\delta 11.9(\mathrm{C}-18)$ and 210.4 (C-23) ppm characteristic of this aglycone. ${ }^{3}$ This data is consistent with the presence of 
several saponin spots in the TLC of fraction F4 and the detection of ions of $m / z 1431,1407$, 1391, 1257 and 1229 in addition to the desodiated anion $(\mathrm{m} / \mathrm{z}$ 1243) of Thornasteroside A (1) (Fig. 2).

Fraction F8 obtained by purification of the $n-\mathrm{BuOH}$ extract of the central disks of $H$. helianthus contained sulfated polyhydroxysteroid glycosides as the major components. The ESIMS of F8 in the negative ion mode (Fig. 4) displays an abundant ion of $\mathrm{m} / z 663$ corresponding to the desodiated anions of isomeric steroidal glycosides $\mathbf{2}$ and $\mathbf{3}$, together with ions of $\mathrm{m} / \mathrm{z}$ 677, 795 and 807, presumably due to desodiated anions of minor polyhydroxylated steroidal glycosides. To investigate their structures, ESI-MS/MS experiments were performed.

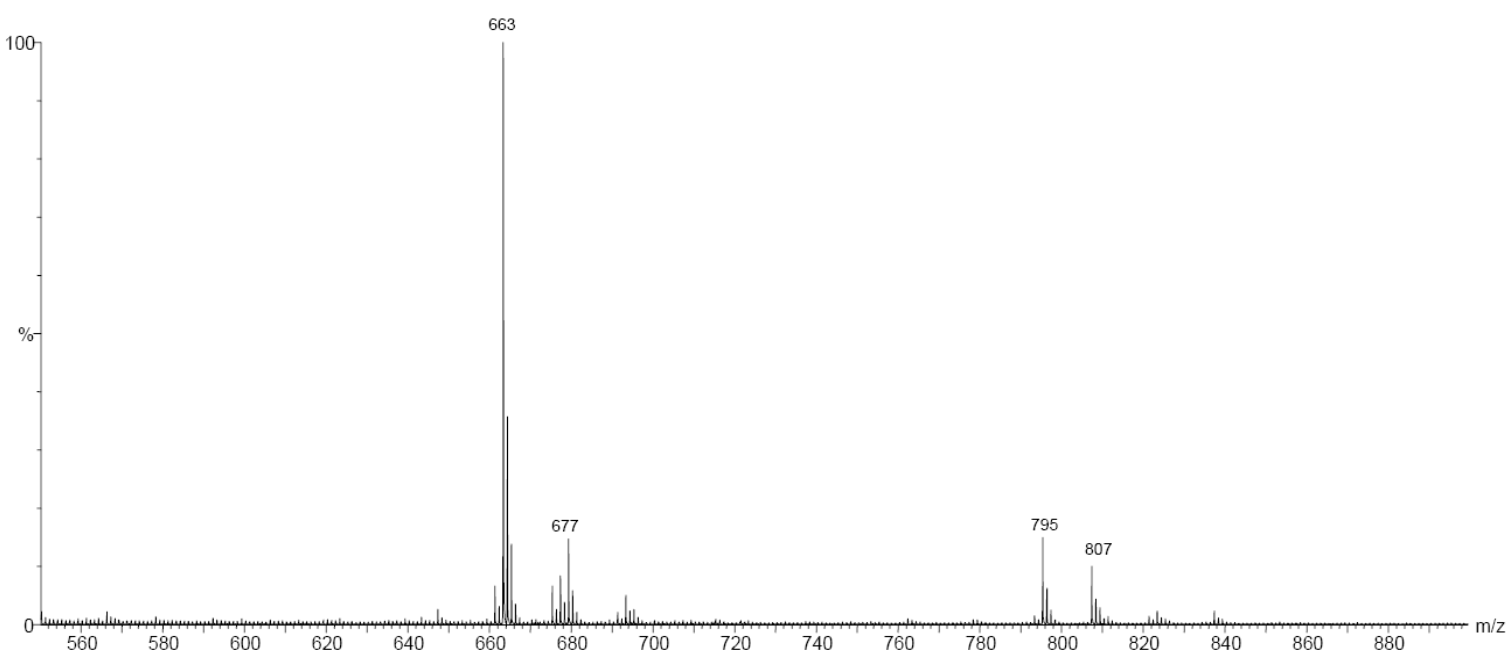

Figure 4. ESI-MS in the negative ion mode of the mixture of polyhydroxylated glycosides in fraction F8.

The ESI-MS/MS of the isolated ion of $m / z 663$ (Fig. 5) shows the $\mathrm{SO}_{4} \mathrm{H}^{-}$of $m / z 97$ as the major fragment together with a fragment ion of $\mathrm{m} / z 211$ assigned to the sulphated xylose unit in Helianthoside (2). 


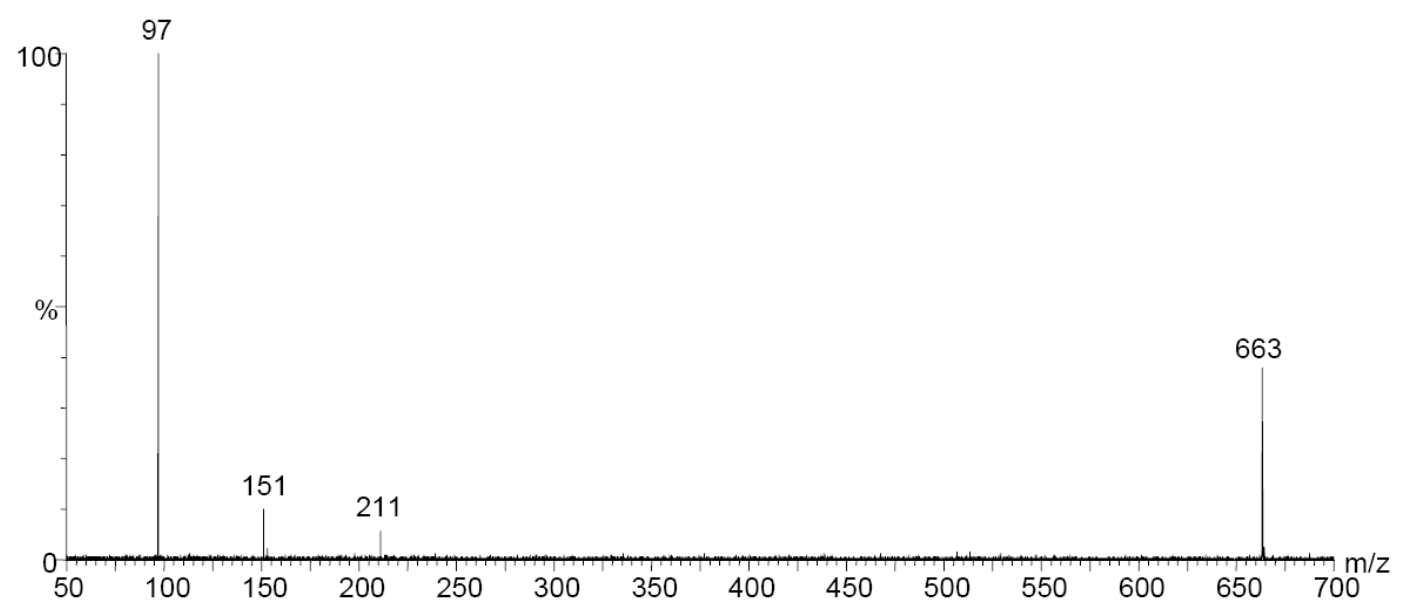

Figure 5. ESI-MS/MS of the ion of $\mathrm{m} / \mathrm{z} 663$.

${ }^{1} \mathrm{H}-\mathrm{NMR}$ analysis of fraction F8 shows diagnostic signals that confirm the presence of glycosides $\mathbf{2}$ and $\mathbf{3}$ in this fraction (Table 1). ${ }^{5}$

Table 1. Selected ${ }^{1} \mathrm{H}$ NMR signals for Helianthoside (2) and its isomer (3) in fraction F8

\begin{tabular}{ccc}
\hline Proton & $\mathbf{2}$ & $\mathbf{3}$ \\
\hline & $\delta(\mathrm{m}, \mathrm{J} \mathrm{Hz})$ & $\delta(\mathrm{m}, \mathrm{J} \mathrm{Hz})$ \\
\hline $\mathrm{H}_{3}-18$ & $1.30(\mathrm{~s})$ & $0.95(\mathrm{~s})$ \\
$\mathrm{H}_{3}-19$ & $1.23(\mathrm{~s})$ & $1.01(\mathrm{~s})$ \\
$\mathrm{H}_{3}-21$ & $1.00(\mathrm{~d}, 6.0)$ & $0.94(\mathrm{~d}, 7.0)$ \\
$\mathrm{H}_{3}-26$ & $1.08(\mathrm{~d}, 6.8)$ & $0.89(\mathrm{~d}, 6.7)$ \\
$\mathrm{H}_{3}-27$ & $1.13(\mathrm{~d}, 6.8)$ & $0.88(\mathrm{~d}, 6.7)$ \\
\hline
\end{tabular}

ESI-MS/MS experiment of the ion of $\mathrm{m} / \mathrm{z} 677$ ion (Fig. 6a) shows it to dissociate mainly to $\mathrm{HSO}_{4}{ }^{-}$of $\mathrm{m} / \mathrm{z} 97$ as well as to a fragment ion of $m / z 529$ by the loss of a pentose unit via $\mathrm{H}$ transfer. This fragmentation pathway indicates that the ion of $m / z 677$ corresponded to a sulfated monoglycoside of a polyhydroxylated steroid 14 Da heavier than Helianthoside (2) and its isomer (3). This mass difference can be attributed to the presence of a methoxy group in one of the sugar residues. This structural feature is very common in polyhydroxysteroid glycosides isolated from starfishes. On the other hand, the ESI-MS/MS of the isolated ion of $\mathrm{m} / z$ 807 (Fig. $6 \mathrm{~b})$ shows it to dissociate to an ion of $\mathrm{m} / \mathrm{z} 657$ by the loss of one pentose unit via $\mathrm{H}$ transfer as well as to a fragment ion of $m / z 211$ as observed in the ESI-MS/MS of the ion of $m / z 663$. This results, together with the detection of $\mathrm{HSO}_{4}{ }^{-}$as the major fragment, are consistent with a sulfated polyhydroxysteroid diglycoside detected as $[\mathrm{M}-\mathrm{Na}]^{-}$of $m / z 807$. 

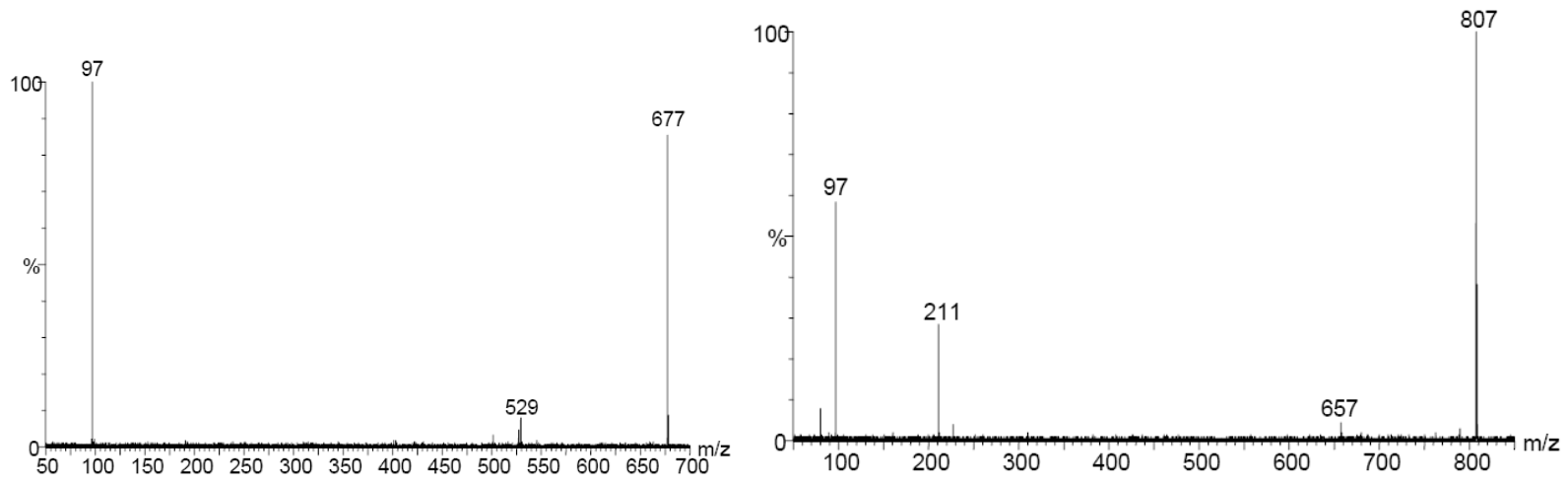

Figure 6. (a) ESI-MS/MS spectrum of ion at $\mathrm{m} / \mathrm{z}$ 677; (b) ESI-MS/MS spectrum of ion at $\mathrm{m} / \mathrm{z}$ 807.

Subsequent ESI-MS/MS of the ion of $\mathrm{m} / z 795$ shows it to dissociate mainly to $\mathrm{HSO}_{4}{ }^{-}$and a fragment ion of $m / z 211$ presumably due to a sulphated pentose unit as in Helianthoside (2). The mass difference between monoglycosides 2 and 3 and the glycoside of $m / z 795$ is 132 Da and corresponds to the mass of a pentose. Hence, the ion of $\mathrm{m} / \mathrm{z} 795$ can be assigned to a sulfated polyhydroxysteroid diglycoside containing two pentose units, one bearing a sulfate group.

\section{Conclusions}

Electrospray ionization mass and tandem mass spectrometries in the negative ion mode is shown to provide a fast and suitable screening method able to characterize underivatized sulfated steroidal glycosides in purified extracts of starfish. The present study indicates that fractions F4 and F8 contain complex mixtures of asterosaponins and sulfated mono- and diglycosides of polyhydroxylated steroids, respectively. ESI-MS and ESI-MS/MS together with NMR data allowed us to confirm the presence of saponins 1-3 in and detect the presence of other minor sulfated steroidal glycosides that may contribute to the toxicity of the starfish.

ESI-MS and ESI-MS/MS have great advantages for chemical screening of complex saponin mixtures. Due to the time-consuming and material-consuming isolation of pure saponins, these methodologies are important tools to obtain information on the complexity of a saponin mixture, the presence of known compounds and the chance of finding new structures. However, because the information is limited on the sugar linkage pattern, site of attachment of sulfate groups and the presence of sugar isomers, only a partial characterization of a new saponin is possible and further studies on the pure compounds using NMR spectroscopy and chemical reactions are required. 


\section{Experimental Section}

General Procedures. ${ }^{1} \mathrm{H}$ and ${ }^{13} \mathrm{C}$ NMR spectra were recorded in Py- $d_{5}$ on a Bruker AM 500 spectrometer. TLC was performed on precoated Si gel F254 (n-BuOH-HOAc- $\left.\mathrm{H}_{2} \mathrm{O}(12: 3: 5)\right)$ and $\mathrm{C}_{18}$ reversed-phase plates $\left(70 \% \mathrm{MeOH}-\mathrm{H}_{2} \mathrm{O}\right)$ and detected by spraying with $p$-anisaldehyde $(5 \%$ EtOH). Samples were analyzed by direct infusion ESI by means of a syringe pump (Harvard Apparatus) at a flow rate of $10 \mu \mathrm{l} / \mathrm{min}$. Negative ion mode ESI-MS fingerprints and negative mode ESI-MS/MS for low energy collision-induced dissociation (CID) were acquired using a hybrid high-resolution and high-accuracy $(5 \mathrm{ppm})$ Micromass Q-TOF mass spectrometer. Capillary and cone voltages were set to $3300 \mathrm{~V}$ and $30 \mathrm{~V}$ respectively, with a desolvation temperature of $100{ }^{\circ} \mathrm{C}$. Each sample was prepared in a solution containing $50 \%(\mathrm{v} / \mathrm{v})$ chromatographic grade methanol (Tedia, Fairfield, OH, USA) and 50\% (v/v) deionized water basified with ammonium hydroxide (Merck, Darmstadt, Germany). Mass spectra were acquired in the range between $\mathrm{m} / \mathrm{z} 100$ and 1400. ESI-MS/MS was performed by selecting the ion of interest using the first quadrupole Q1, which was in turn subjected to $15-35 \mathrm{eV}$ collisions with argon in the second rf-only collision quadrupole (Q2) while scanning the orthogonal TOF mass analyser to acquire its tandem mass spectrum.

Specimens of $H$. helianthus were collected at Las Cruces (V Región, Chile). The organisms were identified by Dr. Claudia Muniain of the Museo de Ciencias Naturales "Bernardino Rivadavia", Buenos Aires, Argentina, where a voucher specimen is preserved (MACN-IN 36525).

Extraction and isolation of steroidal glycosides. The starfish (10 animals, $3.85 \mathrm{~kg}$ ) were defrosted and dissected into their arms $(2.7 \mathrm{~kg})$ and central disks $(1.14 \mathrm{~kg})$. Each portion was cut into small pieces, homogenized in $\mathrm{EtOH}$ and filtered. The $\mathrm{EtOH}$ was evaporated to obtain an aqueous residue that was partitioned between $\mathrm{H}_{2} \mathrm{O}$ and cyclohexane and then between $n$ - $\mathrm{BuOH}$ and $\mathrm{H}_{2} \mathrm{O}$. The $n-\mathrm{BuOH}$ extracts were evaporated under reduced pressure to give glassy materials ( $9.5 \mathrm{~g}$ from the arms and $3.5 \mathrm{~g}$ from the central disks) toxic to the brine shrimp Artemia salina $\left(\mathrm{LD}_{50}: 107.3 \mathrm{ppm}\right.$ and $264.3 \mathrm{ppm}$, respectively). Each $n$-BuOH extract was chromatographed on a Sephadex LH60 column with $\mathrm{MeOH}: \mathrm{H}_{2} \mathrm{O}(2: 1)$ as eluent to give fractions containing mixtures of sulfated saponins. Two of these fractions, F4 $(99 \mathrm{mg})$ and F8 $(139 \mathrm{mg})$ were selected for ESI mass spectrometry studies.

\section{Acknowledgements}

This work was supported partly by CONICET (Consejo Nacional de Investigaciones Científicas y Técnicas) (PIP 5509), ANPCyT (Agencia Nacional de Promoción Científica y Tecnológica) (PICT 14321), and the Universidad de Buenos Aires (X314). R. C. thanks CONICET for a fellowship. M. S. M. and C. M. are Research Members of the National Research Council of Argentina (CONICET). MNE and RH acknowledge grants from FAPESP and CNPq. 


\section{References}

1. Maier, M. S.; Murray, A. P. In: Biomaterials from Aquatic and Terrestrial Organisms; Fingerman, M.; Nagabhushanam, R. Eds.; Science Publishers, 2006, p 559.

2. Verbist, J. F. In: Echinoderm Studies; Jangoux, M.; Lawrence, J. M. Eds. Balkema, 1993; Vol. 4, p 111.

3. (a) Chludil, H. D.; Seldes, A. M.; Maier, M. S. J. Nat. Prod. 2002, 65, 153. (b) Chludil, H. D.; Maier, M. S. J. Nat. Prod. 2005, 68, 1279.

4. Neira, C.; Silva, M.; Iorizzi, M.; Minale, L. Bol. Soc. Chil. Quím. 1992, 37, 139.

5. Vazquez, M. J.; Quiñoa, E.; Riguera, R., San Martín, A. Can. J. Chem. 1993, 71, 1147.

6. Espoz, C.; Castilla, J. C. Mar. Biol. 2000, 137, 887.

7. Centurión, R. L. S. Evaluación del efecto de las saponinas aisladas de Heliaster helianthus (Lamarck, 1816) y Anasterias minuta Perrier 1875: ensayos in situ y bioactividad. FCEyN, UBA, Buenos Aires, 2005.

8. Chludil, H. D.; Seldes, A. M.; Maier, M. S. Res. Adv. in Lipids 2002, $2,9$.

9. (a) Guo, M.; Song, F.; Bai, Y.; Liu, Zh.; Liu, Sh. Anal. Sciences 2002, 18, 481. (b) Broberg, S.; Nord, L. I.; Kenne, L. J. Mass Spectrom. 2004, 39, 691.

10. Meyer, B. N.; Ferrigni, N. R.; Putnam, J. E.; Jacobsen, L. B.; Nichols, D. E.; McLaughlin, J. L. Planta Med. 1982, 45, 31.

11. Minale, L.; Riccio, R.; Zollo, F. In: Progress in the Chemistry of Organic Natural Products; Herz, W.; Kirby, G.W.; Moore, R.E.; Steglich, W.; Tamm CH., Eds.; Springer-Verlag: New York, 1993; Vol. 62, pp. 65-308.

12. Roccatagliata, A. J.; Maier, M. S.; Seldes, A. M.; Iorizzi, M.; Minale, L. J. Nat. Prod. 1994, $57,747$. 